\title{
Telemedicine Readiness across Medical Conditions in a US National Representative Sample of Older Adults
}

Running Title: Effects of Medical Conditions on Telemedicine Readiness

Jorge M. Rodríguez-Fernández, $\mathrm{MD}^{1}$, Emily Danies, $\mathrm{MD}^{2}$, Nicolas Hoertel, $\mathrm{MD}, \mathrm{PhD}^{3,4,5}$, William Galanter, MD, $\mathrm{PhD}^{1}$, Hugo Saner, MD, FESC ${ }^{6}$, Oscar H. Franco, MD, $\mathrm{PhD}^{6}$

${ }^{1}$ University of Illinois at Chicago, Chicago, IL, USA

${ }^{2}$ Humboldt Park Health, Chicago, IL, USA

${ }^{3}$ AP-HP. Centre-Université de Paris, Hôpital Corentin-Celton, DMU Psychiatrie et Addictologie, Issy-les-Moulineaux, France

${ }^{4}$ INSERM, Institut de Psychiatrie et Neurosciences de Paris, UMR_S1266, Paris, France

${ }^{5}$ Université de Paris, Faculté de Santé, UFR de Médecine, Paris, France

${ }^{6}$ Institute of Social and Preventive Medicine (ISPM), University of Bern, Bern, Switzerland

Corresponding Author:

Jorge Mario Rodríguez-Fernández, Department of Neurology, University of Illinois at Chicago, 840 S. Wood St. Room 130 CSN, MC 847 Chicago, IL, 60612, USA. Email: jorgerodf@gmail.co

\section{Funding}

No targeted funding reported. 


\title{
IRB Review
}

Since all the analyses were performed on de-identified NHATS data, which is publicly available for download, IRB Review was not required.

\section{Declaration of Conflicting Interests}

The author(s) declared no potential conflicts of interest with respect to the research, authorship, and/or publication of this article.

\begin{abstract}
Telemedicine has provided older adults the ability to seek care remotely during the coronavirus disease (COVID-19) pandemic. However, it is unclear how diverse medical conditions play a role in telemedicine uptake. A total of 3,379 participants ( $\geq 65$ years) were interviewed in 2018 as part of the National Health and Aging Trends Study. We assessed telemedicine readiness across multiple medical conditions. Most chronic medical conditions and mood symptoms were significantly associated with telemedicine unreadiness, for physical or technical reasons or both, while cancer, hypertension, and arthritis were significantly associated with telemedicine readiness. Our findings suggest that multiple medical conditions play a substantial role in telemedicine uptake among older adults in the US. Therefore, comorbidities should be taken into consideration when promoting and adopting telemedicine technologies among older adults.
\end{abstract}

Keywords: telemedicine, telemedicine readiness, chronic diseases, mood disorders, COVID-19. 


\section{Introduction}

The coronavirus (COVID-19, SARS-CoV-2) pandemic created an unexpected crisis around the globe (Hoertel et al., 2020). Mitigation strategies have led to increased use of telemedicine to provide clinical care while minimizing mortality, economic impact and viral spread, as promoted by the Department of Health and Human Services (Hoertel et al., 2020).

Prior to the pandemic, Medicare and Centers for Medicare and Medicaid Services (CMS) valued the role of telemedicine, but despite efforts to expand its use, this service was limited to specific scenarios. The expansion of telemedicine during the COVID-19 pandemic allowed beneficiaries to receive this service from any location (not just rural areas) and to be reimbursed at levels consistent with in-person visits, as promoted by CMS and Medicare. For example, CMS has allowed the use of 2021 guidelines for the evaluation and management level of service for telemedicine visits, as opposed to prior complex guidelines (Sinsky \& Linzer, 2020). These waivers and incentives allowed an uptake in these services.

Prior studies indicated that older adults accessed telemedicine efficiently (Hawley et al., 2020). Evidence also showed telemedicine-related improvements in health outcomes (Hong et al., 2017; Karhula et al., 2015; Liu et al., 2011; Trief et al., 2013), quality of life (Hägglund et al., 2015; Liu et al., 2011), medication management (Patel et al., 2013; Trief et al., 2013), and health literacy (Liu et al., 2011; Patel et al., 2013) among patients using telehealth prior to the pandemic. However, about $15 \%$ of older adults experienced a disruption in medical care during the pandemic (Patel et al., 2013), and it has been estimated that about 13 million older adults in 
the US may have difficulty using or adopting telemedicine services (Lam et al., 2020); physical and technical barriers, cognitive impairment, frailty and social disparities, which are strongly associated with medical conditions, may play a role (Ellison-Barnes et al., 2021; Foster \& Sethares, 2014; Keränen et al., 2017; Kruse et al., 2020). However, it is not known whether and to what extent there is an association between telemedicine readiness and chronic medical conditions among older adults and how this could impact available adoption models. The Technology Acceptance Model (TAM) and the Unified Theory of Acceptance and Use of Technology (UTAUT) models have been used in the evaluation of telemedicine adoption, and although these focus on end-user acceptance, attention has to be given to medical conditions potentially limiting its adoption in older adults (Harst et al., 2019).

Older adults are at higher risk of having multiple medical conditions and therefore are more likely to seek care (Bähler et al., 2015). Also, chronic medical conditions and mood disorders are associated with increased physical and functional limitations, recurrent hospitalizations, social isolation, and higher health care needs among older adults (Picco et al., 2016; Roland \& Paddison, 2013). In addition, older age and the presence of chronic conditions, such as diabetes, cardiovascular diseases, obesity, and kidney diseases, puts patients at a higher risk of developing serious complications from COVID-19 infection, including death (Gupta et al., 2020; Zhou et al., 2020). Therefore, older adults are encouraged to stay at home and use telemedicine alternatives to continue care.

Prior work on internet use across multiple cohorts of older adults showed greater usage among those with younger age, White race/ethnicity, higher educational level, higher income, good state of health, and multiple diseases (Boulton-Lewis et al., 2007; Carpenter \& Buday, 2007; Greysen et al., 2014; Heart \& Kalderon, 2013; Kim et al., 2019; Levine et al., 2016). Prior 
to the COVID-19 pandemic, US seniors engaged more in telemedicine, contacting physicians or filling prescriptions using telephone, cell phone or computers, despite regulatory restrictions (Levine et al., 2016). In regard to the modality of communication, older adults preferred telephone over videoconference (Levine et al., 2016), and recent work in a Canadian cohort indicated that frailty and absence of a caregiver were associated with lower likelihood for a videoconference assessment in seniors (Liu, Goodarzi, et al., 2020).

To advance our understanding of the relationship between telemedicine use and chronic medical conditions, it is necessary to evaluate the capabilities of older adults to adopt telemedicine alternatives based on their comorbidities. Assessments and education are required to evaluate older adults' abilities to use telemedicine. Therefore, understanding the potential relationships of medical comorbidities with telemedicine readiness can help support evidencebased policy decisions and facilitate telemedicine usage and adoption among older adults. This study will expand the scarce evidence on end-user facilitating or limiting factors on theoretical models evaluating telemedicine acceptance in older adults.

\section{Methods}

\section{Sample}

The present work is a cross-sectional study of community-dwelling participants from the 2018 National Health and Aging Trends Study (NHATS) including 4,977 individuals (Freedman $\&$ Kasper, 2019). Of these, 934 (19\%) participants were excluded because they were noncommunity residents (residential care or nursing home), and 863 (17\%) were excluded because of cognitive decline, as detailed elsewhere (Rodríguez-Fernández, Danies, Martínez-Ortega, \& Chen, 2017). The remaining 3,379 individuals were included in the analysis. The NHATS survey 
protocol was approved by the Johns Hopkins University Institutional Review Board and all participants provided informed consent.

\section{Telemedicine readiness, unreadiness and medical conditions}

Telemedicine readiness was defined as being able to do one of the following: (1) contact medical providers online; (2) handle medical insurance matters online (coverage, compare providers, bill status, or filing a claim); or (3) obtain information about medical conditions online.

Telemedicine unreadiness was defined as having any physical or technical factor that could limit the communication between health care providers and patients. Physical limitations included any of the following: difficulty hearing, difficulty watching television or reading a newspaper even with glasses, or difficulty speaking or making self understood. Technical limitations included not owning a working telecommunication device (computer, cell phone or telephone), not knowing how to use them, or not using email, texting or the internet during the previous month.

Regarding medical conditions, participants or their proxies were asked whether they had been diagnosed with any of the following medical conditions: cancer, myocardial infarction, heart disease (separate from myocardial infarction), hypertension, stroke, diabetes, lung disease, osteoarthritis and osteoporosis. Self-report of chronic conditions shows good diagnostic accuracy against claims and medical records (kappa values ranging from 0.6 to 0.82 ) (Miller et al., 2008). Depression and anxiety were assessed using two validated screening questionnaires: the Patient Health Questionnaire-2 (PHQ-2) and the Generalized Anxiety Disorder-2 scale (GAD-2). We used a PHQ-2 score $\geq 3$ to define substantial depressive symptoms and a GAD-2 score $\geq 3$ for 
anxiety symptoms; both questionnaires are validated clinical tools among older adults (Boyle et al., 2011; Wild et al., 2014).

\section{Statistical analysis}

Demographic characteristics and medical conditions of community-dwelling participants were compared between each telemedicine group (those who met any of the readiness criteria and those who did not) and between those with unreadiness (physical or technical) and those without this condition using $\chi^{2}$ tests. To account for age effects, we dichotomized age as younger than 80 years versus 80 years or older, since the latter group lacks technological exposure and has higher frailty levels, limiting technological implementation and acquisition (Harvie et al., 2014; Harvie et al., 2016). Frequency rates of telemedicine readiness and unreadiness factors across medical conditions were also calculated. Adjusted logistic regression models were used to estimate telemedicine readiness and unreadiness due to physical or technical factors by medical condition. We adjusted for confounding variables including age, gender, race/ethnicity, education and marital status as covariates. For all associations, we performed residual analyses to assess the fit of the data, checked assumptions, and examined the potential influence of outliers. Because our analyses were mainly exploratory, statistical significance was fixed a priori at a two-sided $P$ value $<0.05$. Statistical analyses were conducted using Stata $12 \mathrm{SE}$ version (StataCorp, TX) and in R version 4 (R Foundation for Statistical Computing, Vienna, Austria).

\section{Results}

Demographic characteristics by telemedicine category 
Table 1 shows the demographics, clinical characteristics and medical conditions of the study sample by telemedicine readiness and unreadiness, either physical or technical. Participants categorized as telemedicine-ready were more likely to be married females, younger than 80 years, White Non-Hispanic, with at least a college degree, and less likely to have myocardial infarction, diabetes, cancer, anxiety and depressive symptoms compared to those with no readiness factors. Participants with physical telemedicine unreadiness were more likely to be aged 80 years or older, with a high school diploma or less, and less likely to be White NonHispanic; they were also more likely to have hypertension, myocardial infarction, heart disease, stroke, diabetes, lung disease, osteoarthritis, osteoporosis, and to report anxiety and depressive symptoms compared to those with no physical unreadiness factors. Finally, individuals with technical telemedicine unreadiness were more likely to be unmarried females aged 80 years or older, with a high school diploma, and less likely to be White Non-Hispanic, or to have hypertension, myocardial infarction, heart disease, diabetes, lung disease, osteoarthritis or osteoporosis compared to those with no technical unreadiness factors. They were also more likely to have depressive and anxiety symptoms, but less likely to report history of cancer than were those with no technical unreadiness factors.

\section{Telemedicine factors by medical condition}

Table 2 shows the prevalence of each telemedicine category by medical condition. In regards to telemedicine readiness, looking for medical information online was the most prevalent behavior among those with a history of cancer (38\%) and the least prevalent in those with a history of myocardial infarction and depressive symptoms (13\% and $14 \%$, respectively). The same trend was observed for ability to contact a medical provider online, which was more prevalent in those with history of cancer (29\%) and lower in those with history of myocardial 
infarction $(7 \%)$ and depressive symptoms (13\%). The most prevalent factor for physical unreadiness was difficulty speaking or making self understood, ranging from $6 \%$ in those with hypertension and arthritis to $16 \%$ among stroke survivors, while difficulty watching television or reading a newspaper even with glasses ranged from $2 \%$ in those with history of cancer to $13 \%$ in those who reported myocardial infarction. For technical unreadiness, not using the internet in the previous month ranged from $34 \%$ (cancer) to $55 \%$ (depressive symptoms), not using email or texting in the previous month ranged from $30 \%$ (cancer) to $53 \%$ (depressive symptoms), and not having a working computer ranged from $19 \%$ (cancer) to $49 \%$ (depressive symptoms).

\section{Telemedicine readiness and unreadiness across medical conditions}

Telemedicine readiness was evaluated while adjusting for age, sex, race, marital status and education (Table 3). Telemedicine readiness was significantly and positively associated with history of cancer (odds ratio $[\mathrm{OR}]=1.60,95 \%$ confidence interval $[\mathrm{CI}]=1.19-2.16, P<0.01$ ), arthritis $(\mathrm{OR}=1.21,95 \% \mathrm{CI}=1.01-1.44, P<0.05)$ and hypertension $(\mathrm{OR}=1.22,95 \% \mathrm{CI}=$ $1.02-1.46, P<0.05)$ but negatively associated with depressive symptoms $(\mathrm{OR}=0.61,95 \% \mathrm{CI}=$ $0.44-0.85, P<0.01)$. Telemedicine unreadiness due to a physical factor was significantly and substantially associated with most comorbidities, except for cancer history, with ORs ranging from $1.45(95 \% \mathrm{CI}=1.09-1.95, P<0.05)$ in those with hypertension to $2.52(95 \% \mathrm{CI}=1.37-$ 4.62, $P<0.01)$ in those with myocardial infarction. Telemedicine unreadiness due to technical factors was associated with history of diabetes, heart disease, depressive symptoms, and anxiety symptoms, with ORs ranging from $1.27(95 \% \mathrm{CI}=1.06-1.53, P<0.05)$ to $2.48(95 \% \mathrm{CI}=1.80-$ $3.40, P<0.001)$ in those with heart disease and depressive symptoms, respectively.

\section{Discussion}


Our study identified a significant association between telemedicine readiness and cancer, arthritis, and hypertension; in addition, readiness was challenged by the presence of physical factors and technical factors across medical conditions. These findings support the concept that comorbidities play a role in telemedicine adoption and use among older adults. They also suggest that these factors must be taken into consideration while using end-user technology acceptance models. Several explanations could account for these associations. We know that despite the underlying communication barriers in patients with cancer due to complex medical terminology, type of information given, and older age (McDonald-Miszczak et al., 2005; van Weert et al., 2011), strong efforts to empower these patients to recognize and communicate their needs to healthcare workers have been successful. Prior studies show increased popularity of digital resources among patients with a cancer history (Shea-Budgell et al., 2014), not only to provide information regarding diagnosis and treatment but to continue care after initial treatment, including during remission, recurrence, metastasis, and end of life; this framework is often referred to as the cancer continuum model (Fletcher et al., 2017; Gorin et al., 2017). A recent meta-analysis indicates that telemedicine plays a crucial rule helping to coordinate care over different stages in the model (Gorin et al., 2017), improving symptom management, patient-to-clinician communication, and quality of life and reducing hospitalization (Chumbler, Kobb, et al., 2007; Chumbler, Mkanta, et al., 2007; Mkanta et al., 2007). This has led to opportunities for older adults with cancer to engage in their healthcare, increasing information and communication at the time of diagnosis, treatment or after (Gorin et al., 2017; Shea-Budgell et al., 2014). In regard to arthritis, a systematic review on osteoarthritis and rheumatoid arthritis shows that telemedicine provides an equally effective intervention compared to a traditional clinic visit, such that patients are satisfied with the type and quality of the delivery of care (Piga et al., 2017). In regard to hypertension, meta-analysis and 
systematic review highlight that telemedicine in hypertension is feasible, well-accepted, and able to improve outcomes including blood pressure control in the community setting, even in underserved areas or ethnic minorities (Agarwal et al., 2011; Omboni et al., 2013). A recent manuscript by the American Heart Association on telemedicine and management of hypertension during the pandemic highlights that older adults should be a target population for the development of healthcare models while including remote monitoring, medication adherence and education on lifestyle and risk factors (Omboni et al., 2020). Overall, telemedicine helps to empower patients with cancer, arthritis and hypertension by promoting self-management, improving patientphysician relationship and influencing behaviors and attitudes.

Confirming results from prior studies in older adults, we found that telemedicine unreadiness is more likely to be found in older females who are unmarried, non-White, with a high school degree or less. Also, unreadiness due to technical factors is more prevalent $(\mathrm{N}=1,817)$ than unreadiness due to physical factors ( $\mathrm{N}=344)$. Conversely, telemedicine readiness is found in $34 \%$ of the cohort $(\mathrm{N}=1,145)$ and is more common among younger females who are married, White, with a college degree or beyond (Foster \& Sethares, 2014; Greysen et al., 2014; Heart \& Kalderon, 2013; Kruse et al., 2020; Levine et al., 2016).

Previous studies demonstrate telemedicine barriers in older adults including technical issues, physical factors, frailty and social disparities (Ellison-Barnes et al., 2021; Keränen et al., 2017; Patel et al., 2013), limiting the use of videoconference compared to telephone visits in telemedicine (Lam et al., 2020; Stevens et al., 2021). In addition, recent studies during the pandemic report that despite interest in telemedicine adoption, the aging population has lower use compared to younger individuals, mostly due to technical limitations (Fischer et al., 2020; Horrell et al., 2021). In our study, physical factors across most comorbidities are associated with 
unreadiness; this finding is consistent with prior research on cardiovascular, pulmonary, inflammatory or mood disorders leading to physical limitations (de Matos Nascimento et al., 2015; Eisner et al., 2008; Hawker, 2019; King et al., 2018; Lenze et al., 2001; Welmer et al., 2013). In addition, it has been noted that subjects with visual, hearing or communication problems are more likely to suffer from the conditions above (Flowers et al., 2016; Grosmaitre et al., 2013; Mulrow et al., 1990; Rovner \& Ganguli, 1998); furthermore, sense impairment is known to lead to communication difficulties (Jonas \& Loeb, 2010). Technical limitations are observed in heart disease, diabetes and mood disorders; although prior trials show the feasibility of device usage (mobile or telephone) for health communication or monitoring across different comorbidities in older adults (Raphael et al., 2017), our study highlights that these comorbidities might entail technical challenges for telemedicine adoption. For example, a recent literature review on diabetes care and eHealth indicates that lack of technological skills, computer access, resistance to change given mistrust in care and privacy concerns can limit final implementation (Gurung \& Neupaney, 2020). The same has been noted among patients with heart disease, where difficulty operating technology can account for up to 75\% of refusals (Anglada-Martínez et al., 2016; Karhula et al., 2015). Therefore, certain studies use telemedicine alternatives to complement regular care (Goyal et al., 2016).

Of note, few medical conditions among older adults have an impact on unreadiness for telemedicine, including both technical and physical limitations. Depressive and anxiety symptoms have the strongest association, followed by history of heart disease and diabetes. Telemedicine alternatives in mental health care can facilitate therapy delivery, information resources, counseling and networking (Cooper, 2013; Dölemeyer et al., 2013; So et al., 2013). Despite these efforts, challenges remain, including technical issues, awareness of telemedicine options, end-user 
friendliness, privacy, functionality and mental health wellbeing (Fulford et al., 2016; Vis et al., 2018). Furthermore, physical impairments are often associated with mood symptoms (Mulrow et al., 1990; Rovner \& Ganguli, 1998). Barriers to remote mental health care have initiated efforts to understand such factors. A systematic review on the topic highlights two determinants that affect telemedicine adoption beyond technical issues: first, building mutual expectations and preferences, and second, developing interventions tailored for telemedicine, promoting adequate patient-toprovider interaction (Vis et al., 2018).

Our results have multiple implications. First, they suggest that clinicians should be aware that older adults with chronic conditions or mood symptoms face limitations for telemedicine access and adoption, extending prior work on the barriers for telemedicine among older adults (Foster \& Sethares, 2014; Kruse et al., 2020). Conversely, patients with cancer, hypertension and arthritis seem to be better prepared for telemedicine. Our findings also suggest the potential value of optimizing and facilitating telemedicine acceptance while evaluating readiness and unreadiness, factors that should be considered in conjunction with the proposed telemedicine implementation models such as TAM, UTAUT and the Senior Technology Acceptance Model (STAM) (Chen \& Chan, 2014; Hoque \& Sorwar, 2017). Design considerations accounting for unreadiness factors by comorbidity must be taken into account to enhance usability. In addition, given social distancing recommendations, remote monitoring systems using a copresence-enhanced model might be beneficial to monitor health-related data among older adults with chronic medical conditions (Liu, Huang, et al., 2020). Our results suggest that assessing, implementing, and evaluating strategies to optimize equitable access to telemedicine among older adults are important to minimize the gap of care across medical comorbidities. 
The strengths of our study include a relatively large sample size and its representativeness. Results should also be interpreted in the light of limitations common to most large-scale surveys. First, diagnoses of medical conditions relied on patient report and were not confirmed by independent physician assessment, leading to increased variance and attenuation of correlations; nonetheless, self-report of chronic conditions has good diagnostic accuracy against claims and medical records (Miller et al., 2008). Furthermore, reporting devices or technical issues can potentially lead to over- or underestimation of the true rates of readiness or unreadiness. Second, severity and possible consequences of telemedicine unreadiness were not evaluated, leaving the impact on older adults' health over time unclear. Longitudinal data are needed to examine the course of those barriers and to evaluate older adults' responses to either unreadiness or readiness.

Despite these limitations, our study constitutes a critical step in the understanding of medical conditions and mood symptoms and their impact on telemedicine unreadiness and readiness in the US. We found that in a large and nationally representative sample of older US adults, common medical conditions and mood symptoms were associated with telemedicine unreadiness, whereas cancer, hypertension and arthritis were associated with telemedicine readiness. Given the ongoing efforts to provide and enhance care through telemedicine for older adults during the COVID-19 pandemic, these results suggest that more attention may be needed to comorbidities among older adults to facilitate telemedicine usage and adoption.

\section{References}


Agarwal, R., Bills, J. E., Hecht, T. J., \& Light, R. P. (2011). Role of home blood pressure monitoring in overcoming therapeutic inertia and improving hypertension control: a systematic review and meta-analysis. Hypertension, 57(1), 29-38.

Anglada-Martínez, H., Rovira-Illamola, M., Martin-Conde, M., Sotoca-Momblona, J. M., \& Codina-Jané, C. (2016). mHealth intervention to improve medication management in chronically ill patients: analysis of the recruitment process. Postgraduate Medicine, $128(4), 427-431$.

Bähler, C., Huber, C. A., Brüngger, B., \& Reich, O. (2015). Multimorbidity, health care utilization and costs in an elderly community-dwelling population: a claims data based observational study. BMC Health Services Research, 15(1), 23.

Boulton-Lewis, G. M., Buys, L., Lovie-Kitchin, J., Barnett, K., \& David, L. N. (2007). Ageing, learning, and computer technology in Australia. Educational Gerontology, 33(3), $253-270$.

Boyle, L. L., Richardson, T. M., He, H., Xia, Y., Tu, X., Boustani, M., \& Conwell, Y. (2011). How do the phq-2, the phq-9 perform in aging services clients with cognitive impairment? International Journal of Geriatric Psychiatry, 26(9), 952-960.

Carpenter, B. D., \& Buday, S. (2007). Computer use among older adults in a naturally occurring retirement community. Computers in Human Behavior, 23(6), 3012-3024.

Chen, K., \& Chan, A. H. S. (2014). Gerontechnology acceptance by elderly Hong Kong Chinese: a senior technology acceptance model (STAM). Ergonomics, 57(5), 635-652. Chumbler, N. R., Kobb, R., Harris, L., Richardson, L. C., Darkins, A., Sberna, M., Dixit, N., Ryan, P., Donaldson, M., \& Kreps, G. L. (2007). Healthcare utilization among 
veterans undergoing chemotherapy: the impact of a cancer care coordination/hometelehealth program. The Journal of Ambulatory Care Management, 30(4), 308-317. Chumbler, N. R., Mkanta, W. N., Richardson, L. C., Harris, L., Darkins, A., Kobb, R., \& Ryan, P. (2007). Remote patient-provider communication and quality of life: empirical test of a dialogic model of cancer care. Journal of Telemedicine and Telecare, 13(1), 2025.

Cooper, A. (2013). Using social networks to help patients self-care. Nursing Times, 109(10), 22-24.

de Matos Nascimento, C., de Melo Mambrini, J. V., de Oliveira, C. M., Giacomin, K. C., \& Peixoto, S. V. (2015). Diabetes, hypertension and mobility among Brazilian older adults: findings from the Brazilian National Household Sample Survey (1998, 2003 and 2008). BMC Public Health, 15(1), 591.

Dölemeyer, R., Tietjen, A., Kersting, A., \& Wagner, B. (2013). Internet-based interventions for eating disorders in adults: a systematic review. BMC Psychiatry, 13(1), 207.

Eisner, M. D., Blanc, P. D., Yelin, E. H., Sidney, S., Katz, P. P., Ackerson, L., Lathon, P., Tolstykh, I., Omachi, T., Byl, N., \& Iribarren, C. (2008). COPD as a systemic disease: impact on physical functional limitations. The American Journal of Medicine, 121(9), 789-796.

Ellison-Barnes, A., Moran, A., Linton, S., Chaubal, M., Missler, M., \& Pollack, C. E. (2021). Limited Technology Access Among Residents of Affordable Senior Housing During the COVID-19 Pandemic. Journal of Applied Gerontology, 07334648211013634. 
Fischer, S. H., Ray, K. N., Mehrotra, A., Bloom, E. L., \& Uscher-Pines, L. (2020). Prevalence and characteristics of Telehealth utilization in the United States. JAMA Network Open, 3(10), e2022302-e2022302.

Fletcher, C., Flight, I., Chapman, J., Fennell, K., \& Wilson, C. (2017). The information needs of adult cancer survivors across the cancer continuum: a scoping review. Patient Education and Counseling, 100(3), 383-410.

Flowers, H. L., Skoretz, S. A., Silver, F. L., Rochon, E., Fang, J., Flamand-Roze, C., \& Martino, R. (2016). Poststroke aphasia frequency, recovery, and outcomes: a systematic review and meta-analysis. The Archives of Physical Medicine and Rehabilitation, 97(12), 2188-2201. e2188.

Foster, M. V., \& Sethares, K. A. (2014). Facilitators and barriers to the adoption of telehealth in older adults: an integrative review. CIN: Computers, Informatics, Nursing, $32(11), 523-533$.

Freedman, V. A., \& Kasper, J. D. (2019). Cohort profile: the national health and aging trends study (NHATS). International Journal of Epidemiology, 48(4), 1044.

Fulford, H., McSwiggan, L., Kroll, T., \& MacGillivray, S. (2016). Exploring the use of information and communication technology by people with mood disorder: a systematic review and metasynthesis. JMIR Mental Health, 3(3), e30.

Gorin, S. S., Haggstrom, D., Han, P. K., Fairfield, K. M., Krebs, P., \& Clauser, S. B. (2017). Cancer care coordination: a systematic review and meta-analysis of over 30 years of empirical studies. Annals of Behavioral Medicine, 51(4), 532-546. 
Goyal, S., Morita, P. P., Picton, P., Seto, E., Zbib, A., \& Cafazzo, J. A. (2016). Uptake of a consumer-focused mHealth application for the assessment and prevention of heart disease: the $<30$ days study. JMIR mHealth and uHealth, 4(1), e32.

Greysen, S. R., Garcia, C. C., Sudore, R. L., Cenzer, I. S., \& Covinsky, K. E. (2014). Functional impairment and Internet use among older adults: implications for meaningful use of patient portals. JAMA Internal Medicine, 174(7), 1188-1190.

Grosmaitre, P., Le Vavasseur, O., Yachouh, E., Courtial, Y., Jacob, X., Meyran, S., \& Lantelme, P. (2013). Significance of atypical symptoms for the diagnosis and management of myocardial infarction in elderly patients admitted to emergency departments. Archives of Cardiovascular Diseases, 106(11), 586-592.

Gupta, R. K., Marks, M., Samuels, T. H., Luintel, A., Rampling, T., Chowdhury, H., Quartagno, M., Nair, A., Lipman, M., Abubakar, I., van Smeden, M., Wong, W. K., Williams, B., \& Noursadeghi, M. (2020). Systematic evaluation and external validation of 22 prognostic models among hospitalised adults with COVID-19: An observational cohort study. European Respiratory Journal, 56(6).

Gurung, S., \& Neupaney, P. (2020). Use of information and communication technology in diabetes management: a descriptive literature review. $\mathrm{PhD}$ Thesis, LAB University of Applied Sciences.

Hägglund, E., Lyngå, P., Frie, F., Ullman, B., Persson, H., Melin, M., \& Hagerman, I. (2015). Patient-centred home-based management of heart failure: findings from a randomised clinical trial evaluating a tablet computer for self-care, quality of life and effects on knowledge. Scandinavian Cardiovascular Journal, 49(4), 193-199. 
Harst, L., Lantzsch, H., \& Scheibe, M. (2019). Theories predicting end-user acceptance of telemedicine use: systematic review. Journal of Medical Internet Research, 21(5), e13117.

Harvie, G., Burmeister, O., \& Eustace, K. (2014). Bringing the oldest-old into the digital age: Overcoming challenges of mobility, literacy, and learning. Paper presented at the 13th National Conference of Emerging Researchers in Ageing.

Harvie, G., Eustace, K., \& Burmeister, O. K. (2016). Assistive technology devices for the oldest-old: Maintaining independence for the fourth age. Paper presented at the IFIP International Conference on Human Choice and Computers.

Hawker, G. A. (2019). Osteoarthritis is a serious disease. Clinical and Experimental Rheumatology, 37(120), S3-S6.

Hawley, C. E., Genovese, N., Owsiany, M. T., Triantafylidis, L. K., Moo, L. R., Linsky, A. M., Sullivan, J. L., \& Paik , J. M. (2020). Rapid integration of home telehealth visits amidst COVID-19: what do older adults need to succeed? Journal of the American Geriatrics Society, 68(11), 2431-2439.

Heart, T., \& Kalderon, E. (2013). Older adults: are they ready to adopt health-related ICT? International Journal of Medical Informatics, 82(11), e209-e231.

Hoertel, N., Blachier, M., Blanco, C., Olfson, M., Massetti, M., Rico, M. S., Limosin, F., \& Leleu, H. (2020). A stochastic agent-based model of the SARS-CoV-2 epidemic in France. Nature Medicine, 26(9), 1417-1421.

Hong, J., Kim, J., Kim, S. W., \& Kong, H.-J. (2017). Effects of home-based tele-exercise on sarcopenia among community-dwelling elderly adults: Body composition and functional fitness. Experimental Gerontology, 87, 33-39. 
Hoque, R., \& Sorwar, G. (2017). Understanding factors influencing the adoption of mHealth by the elderly: An extension of the UTAUT model. International Journal of Medical Informatics, 101, 75-84.

Horrell, L. N., Hayes, S., Herbert, L. B., MacTurk, K., Lawhon, L., Valle, C. G., \& Bhowmick, A. (2021). Telemedicine use and health-related concerns of patients with chronic conditions during COVID-19: Survey of members of online health communities. Journal of Medical Internet Research, 23(2), e23795.

Jonas, B. S., \& Loeb, M. (2010). Mood disorders and physical functioning difficulties as predictors of complex activity limitations in young US adults. Disability and Health Journal, 3(3), 171-178.

Karhula, T., Vuorinen, A.-L., Rääpysjärvi, K., Pakanen, M., Itkonen, P., Tepponen, M., Junno, U.-M., Jokinen, T., van Gils, M., Lähteenmäki, J., Kari Kohtamäki, K., \& Saranummi, N. (2015). Telemonitoring and mobile phone-based health coaching among Finnish diabetic and heart disease patients: randomized controlled trial. The Journal of Medical Internet Research, 17(6), e153.

Keränen, N. S., Kangas, M., Immonen, M., Similä, H., Enwald, H., Korpelainen, R., \& Jämsä, T. (2017). Use of information and communication technologies among older people with and without frailty: a population-based survey. The Journal of Medical Internet Research, 19(2), e29.

Kim, E., Gellis, Z. D., Bradway, C., \& Kenaley, B. (2019). Key determinants to using telehealth technology to serve medically ill and depressed homebound older adults. Journal of Gerontological Social Work, 62(4), 451-474. 
King, L. K., Kendzerska, T., Waugh, E. J., \& Hawker, G. A. (2018). Impact of osteoarthritis on difficulty walking: a population-based study. Arthritis Care and Research, 70(1), 71-79.

Kruse, C., Fohn, J., Wilson, N., Patlan, E. N., Zipp, S., \& Mileski, M. (2020). Utilization barriers and medical outcomes Commensurate with the use of telehealth among older adults: systematic review. JMIR Medical Informatics, 8(8), e20359.

Lam, K., Lu, A. D., Shi, Y., \& Covinsky, K. E. (2020). Assessing telemedicine unreadiness among older adults in the United States during the COVID-19 pandemic. JAMA Internal Medicine, 180(10), 1389-1391.

Lenze, E. J., Rogers, J. C., Martire, L. M., Mulsant, B. H., Rollman, B. L., Dew, M. A., Schulz, R., \& Reynolds, C. F., 3rd. (2001). The association of late-life depression and anxiety with physical disability: a review of the literature and prospectus for future research. The American Journal of Geriatric Psychiatry, 9(2), 113-135.

Levine, D. M., Lipsitz, S. R., \& Linder, J. A. (2016). Trends in seniors' use of digital health technology in the United States, 2011-2014. JAMA, 316(5), 538-540.

Liu, N., Huang, R., Baldacchino, T., Sud, A., Sud, K., Khadra, M., \& Kim, J. (2020). Telehealth for noncritical patients with chronic diseases during the COVID-19 pandemic. Journal of Medical Internet Research, 22(8), e19493.

Liu, L., Goodarzi, Z., Jones, A., Posno, R., Straus, S., \& Watt, J. (2020). Factors associated with access to virtual care in older adults: A cross-sectional study. medRxiv. Liu, W.-T., Huang, C.-D., Wang, C.-H., Lee, K.-Y., Lin, S. M., \& Kuo, H. P. (2011). A mobile telephone-based interactive self-care system improves asthma control. European Respiratory Journal, 37(2), 310-317. 
McDonald-Miszczak, L., Neupert, S. D., \& Gutman, G. (2005). Younger-old and olderold adults' recall of medication instructions. Canadian Journal on Aging, 24(4), 409-417. Miller, D. R., Rogers, W. H., Kazis, L. E., Spiro III, A., Ren, X. S., \& Haffer, S. C. (2008). Patients' self-report of diseases in the Medicare Health Outcomes Survey based on comparisons with linked survey and medical data from the Veterans Health Administration. The Journal of Ambulatory Care Management, 31(2), 161-177.

Mkanta, W. N., Chumbler, N. R., Richardson, L. C., \& Kobb, R. F. (2007). Age-related differences in quality of life in cancer patients: a pilot study of a cancer care coordination/home-telehealth program. Cancer Nursing, 30(6), 434-440. Mulrow, C. D., Aguilar, C., Endicott, J. E., Tuley, M. R., Velez, R., Charlip, W. S., Rhodes, M. C., Hill, J. A., \& DeNino, L. A. (1990). Quality-of-life changes and hearing impairment: a randomized trial. Annals of Internal Medicine, 113(3), 188-194.

Omboni, S., Gazzola, T., Carabelli, G., \& Parati, G. (2013). Clinical usefulness and cost effectiveness of home blood pressure telemonitoring: meta-analysis of randomized controlled studies. Journal of Hypertension, 31(3), 455-468.

Omboni, S., McManus, R. J., Bosworth, H. B., Chappell, L. C., Green, B. B., Kario, K., Logan, A. G., Magid, D. J., Mckinstry, B., Margolis, K. L., Parati, G., \& Wakefield, B. J. (2020). Evidence and recommendations on the use of telemedicine for the management of arterial hypertension: an international expert position paper. Hypertension, 76(5), $1368-1383$.

Patel, S., Jacobus-Kantor, L., Marshall, L., Ritchie, C., Kaplinski, M., Khurana, P. S., \& Katz, R. J. (2013). Mobilizing your medications: an automated medication reminder 
application for mobile phones and hypertension medication adherence in a high-risk urban population. Journal of Diabetes Science and Technology, 7(3), 630-639.

Picco, L., Achilla, E., Abdin, E., Chong, S. A., Vaingankar, J. A., McCrone, P., Chua, H. C., Heng, D., Magadi, H., Ng, L. L., Prince, M., \& Subramaniam, M. (2016). Economic burden of multimorbidity among older adults: impact on healthcare and societal costs. BMC Health Services Research, 16(1), 173.

Piga, M., Cangemi, I., Mathieu, A., \& Cauli, A. (2017). Telemedicine for patients with rheumatic diseases: systematic review and proposal for research agenda. Seminars in Arthritis and Rheumatism, 47, 121-128.

Raphael, D., Waterworth, S., \& Gott, M. (2017). Telephone communication between practice nurses and older patients with long term conditions-a systematic review. Journal of Telemedicine and Telecare, 23(1), 142-148.

Rodríguez-Fernández, J. M., Danies, E., Martínez-Ortega, J., \& Chen, W. C. (2017). Cognitive Decline, Body Mass Index, and Waist Circumference in Community-Dwelling Elderly Participants: Results From a Nationally Representative Sample. Journal of Geriatric Psychiatry and Neurology, 30(2), 67-76.

Roland, M., \& Paddison, C. (2013). Better management of patients with multimorbidity. The BMJ, 346, f2510.

Rovner, B. W., \& Ganguli, M. (1998). Depression and disability associated with impaired vision: the MoVies Project. Journal of the American Geriatrics Society, 46(5), 617-619. Shea-Budgell, M., Kostaras, X., Myhill, K., \& Hagen, N. (2014). Information needs and sources of information for patients during cancer follow-up. Current Oncology, 21(4), 165. 
Sinsky, C., \& Linzer, M. (2020). Practice And Policy Reset Post-COVID-19: Reversion, Transition, Or Transformation? Commentary examines possible policy and practice changes for health professionals, regulators, and payers after the COVID-19 pandemic. Health Affairs, 39(8), 1405-1411.

So, M., Yamaguchi, S., Hashimoto, S., Sado, M., Furukawa, T. A., \& McCrone, P. (2013). Is computerised CBT really helpful for adult depression?-A meta-analytic reevaluation of CCBT for adult depression in terms of clinical implementation and methodological validity. BMC Psychiatry, 13(1), 113.

Stevens, J. P., Mechanic, O., Markson, L., O'Donoghue, A., \& Kimball, A. B. (2021). Telehealth Use by Age and Race at a Single Academic Medical Center During the COVID-19 Pandemic: Retrospective Cohort Study. Journal of Medical Internet Research, 23(5), e23905.

Trief, P. M., Izquierdo, R., Eimicke, J. P., Teresi, J. A., Goland, R., Palmas, W., Shea, S., \& Weinstock, R. S. (2013). Adherence to diabetes self care for white, African-American and Hispanic American telemedicine participants: 5 year results from the IDEATel project. Ethnicity and Health, 18(1), 83-96.

van Weert, J. C., van Noort, G., Bol, N., van Dijk, L., Tates, K., \& Jansen, J. (2011). Tailored information for cancer patients on the Internet: effects of visual cues and language complexity on information recall and satisfaction. Patient Education and Counseling, 84(3), 368-378.

Vis, C., Mol, M., Kleiboer, A., Bührmann, L., Finch, T., Smit, J., \& Riper, H. (2018). Improving implementation of eMental health for mood disorders in routine practice: systematic review of barriers and facilitating factors. JMIR Mental Health, 5(1), e20. 
Welmer, A.-K., Angleman, S., Rydwik, E., Fratiglioni, L., \& Qiu, C. (2013). Association of cardiovascular burden with mobility limitation among elderly people: a populationbased study. PLoS One, 8(5), e65815.

Wild, B., Eckl, A., Herzog, W., Niehoff, D., Lechner, S., Maatouk, I., Schellberg, D., Brenner, H., Müller, H., \& Löwe, B. (2014). Assessing generalized anxiety disorder in elderly people using the GAD-7 and GAD-2 scales: results of a validation study. The American Journal of Geriatric Psychiatry, 22(10), 1029-1038.

Zhou, F., Yu, T., Du, R., Fan, G., Liu, Y., Liu, Z., Xiang, J., Wang, Y., Song, B., Gu, X., Guan, L., Wei, Y., Li, H., Wu, X., Xu, J., Tu, S., Zhang, Y., Chen, H., \& Cao, B. (2020). Clinical course and risk factors for mortality of adult inpatients with COVID-19 in Wuhan, China: a retrospective cohort study. The Lancet, 395(10229), 1054-1062. 


\begin{tabular}{|c|c|c|c|c|c|c|c|c|c|c|c|c|c|c|c|}
\hline $\begin{array}{l}\text { Characteristics }^{\mathrm{a}} \\
\text { Age }\end{array}$ & \multicolumn{2}{|c|}{$\begin{array}{c}\text { Any readiness } \\
\text { factors }(\mathrm{N}=1,145)\end{array}$} & \multicolumn{2}{|c|}{$\begin{array}{c}\text { No readiness } \\
\text { factors }(\mathrm{N}=2,234)\end{array}$} & $\begin{array}{l}P \text { Value* } \\
<0.001\end{array}$ & \multicolumn{2}{|c|}{$\begin{array}{l}\text { Any physical } \\
\text { unreadiness factors } \\
(\mathrm{N}=344)\end{array}$} & \multicolumn{2}{|c|}{$\begin{array}{l}\text { No physical } \\
\text { unreadiness factors } \\
(\mathrm{N}=3,035)\end{array}$} & $\begin{array}{l}P \text { Value* } \\
<0.001\end{array}$ & \multicolumn{2}{|c|}{$\begin{array}{l}\text { Any technical } \\
\text { unreadiness factors } \\
(\mathrm{N}=1817)\end{array}$} & \multicolumn{2}{|c|}{$\begin{array}{l}\text { No technical } \\
\text { unreadiness factors } \\
(\mathrm{N}=1562)\end{array}$} & $\begin{array}{c}P \text { Value* } \\
<0.001\end{array}$ \\
\hline$<80$ & 776 & $(67.8)$ & 1,097 & $(49.1)$ & & 148 & (43) & 1,725 & $(56.8)$ & & 806 & (44.4) & 1,067 & $(68.3)$ & \\
\hline$\geq 80$ & 369 & (32.2) & 1,137 & $(50.9)$ & & 196 & (57) & 1,310 & $(43.2)$ & & 1,011 & (55.6) & 495 & $(31.7)$ & \\
\hline Gender & & & & & $<0.001$ & & & & & 0.874 & & & & & $<0.001$ \\
\hline Male & 550 & (48) & 900 & (40.3) & & 149 & (43.3) & 1,301 & $(42.9)$ & & 717 & (39.5) & 733 & $(46.9)$ & \\
\hline Female & 595 & (52) & 1,334 & (59.7) & & 195 & (56.7) & 1,734 & (57.1) & & 1,100 & $(60.5)$ & 829 & $(53.1)$ & \\
\hline Race/ethnicity & & & & & $<0.001$ & & & & & $<0.001$ & & & & & $<0.001$ \\
\hline White, Non- Hispanic & 977 & (86.3) & 1,483 & $(67.2)$ & & 220 & $(64.3)$ & 2,240 & (74.8) & & 1,133 & $(63.1)$ & 1,327 & $(86.1)$ & \\
\hline African American, Non- Hispanic & 112 & $(9.9)$ & 514 & (23.3) & & 75 & (21.9) & 551 & (18.4) & & 472 & (26.3) & 154 & (10) & \\
\hline Other, Non- Hispanic & 19 & $(1.7)$ & 65 & (2.9) & & 15 & (4.4) & 69 & (2.3) & & 55 & $(3.1)$ & 29 & (1.9) & \\
\hline Hispanic & 24 & $(2.1)$ & 144 & $(6.5)$ & & 32 & (9.4) & 136 & $(4.5)$ & & 136 & (7.6) & 32 & $(2.1)$ & \\
\hline Marital status & & & & & $<0.001$ & & & & & 0.167 & & & & & $<0.001$ \\
\hline Unmarried & 464 & $(40.5)$ & 1,283 & (57.4) & & 190 & $(55.2)$ & 1,557 & (51.3) & & 1,137 & $(62.6)$ & 610 & $(39.1)$ & \\
\hline Married & 681 & (59.5) & 951 & $(42.6)$ & & 154 & $(44.8)$ & 1,478 & (48.7) & & 680 & (37.4) & 952 & $(60.9)$ & \\
\hline Education status & & & & & $<0.001$ & & & & & $<0.001$ & & & & & $<0.001$ \\
\hline High school graduate or less & 82 & (15.6) & 581 & (52.4) & & 95 & (56.2) & 568 & $(38.8)$ & & 550 & (57.6) & 113 & (16.6) & \\
\hline College graduate & 444 & (84.4) & 527 & (47.6) & & 74 & (43.8) & 897 & (61.2) & & 405 & $(42.4)$ & 566 & (83.4) & \\
\hline \multicolumn{16}{|l|}{ Medical condition } \\
\hline Hypertension & 831 & (72.6) & 1,665 & (74.5) & 0.221 & 281 & (81.7) & 2,215 & (73) & $<0.001$ & 1,406 & (77.4) & 1,090 & (69.8) & $<0.001$ \\
\hline Myocardial Infarction & 11 & (1) & 49 & $(2.2)$ & $<0.01$ & 15 & $(4.4)$ & 45 & $(1.5)$ & $<0.001$ & 44 & (2.4) & 16 & (1) & $<0.01$ \\
\hline Heart Disease ${ }^{b}$ & 269 & (23.5) & 536 & (24) & 0.726 & 121 & $(35.2)$ & 684 & (22.6) & $<0.001$ & 463 & $(25.5)$ & 342 & (21.9) & $<0.05$ \\
\hline Stroke & 21 & (1.8) & 48 & $(2.1)$ & 0.541 & 14 & $(4.1)$ & 55 & $(1.8)$ & $<0.005$ & 45 & $(2.5)$ & 24 & $(1.5)$ & 0.054 \\
\hline Diabetes & 275 & (24) & 703 & $(31.5)$ & $<0.001$ & 131 & $(38.2)$ & 847 & (27.9) & $<0.001$ & 626 & $(34.5)$ & 352 & $(22.5)$ & $<0.001$ \\
\hline Cancer & 107 & (9.3) & 121 & (5.4) & $<0.001$ & 25 & (7.3) & 203 & $(6.7)$ & 0.679 & 108 & (6) & 120 & (7.7) & $<0.05$ \\
\hline Lung Disease & 253 & (22.1) & 508 & (22.7) & 0.667 & 114 & $(33.2)$ & 647 & (21.3) & $<0.001$ & 438 & (24.1) & 323 & (20.7) & $<0.05$ \\
\hline Osteoarthritis & 823 & (71.9) & 1,645 & (73.7) & 0.258 & 290 & $(84.5)$ & 2,178 & (71.8) & $<0.001$ & 1,390 & (76.6) & 1,078 & (69) & $<0.001$ \\
\hline Osteoporosis & 375 & (32.8) & 764 & (34.2) & 0.399 & 149 & (43.6) & 990 & (32.6) & $<0.001$ & 629 & (34.7) & 510 & (32.7) & 0.224 \\
\hline Depression & 57 & (5) & 255 & (11.5) & $<0.001$ & 56 & (16.5) & 256 & $(8.5)$ & $<0.001$ & 246 & (13.7) & 66 & $(4.2)$ & $<0.001$ \\
\hline Anxiety & 55 & $(4.8)$ & 193 & (8.7) & $<0.001$ & 50 & (14.7) & 198 & (6.6) & $<0.001$ & 182 & (10.1) & 66 & $(4.2)$ & $<0.001$ \\
\hline
\end{tabular}

*Each $P$ Value represents the comparison between each readiness or unreadiness subgroup using $\chi^{2}$ tests.

${ }^{a}$ Data are given as number (percentage) for each group.

${ }^{b}$ Heart Disease is separate from myocardial infarction. 
Table 2. Telemedicine factors by medical condition

\begin{tabular}{|c|c|c|c|c|c|c|c|c|c|c|c|c|c|c|c|c|c|c|c|c|c|c|}
\hline \multirow{2}{*}{$\begin{array}{l}\text { Telemedicine Factors }^{\mathrm{a}} \\
\text { Readiness }\end{array}$} & \multicolumn{2}{|c|}{$\begin{array}{c}\text { Hypertension } \\
(\mathrm{N}=2,496)\end{array}$} & \multicolumn{2}{|c|}{$\begin{array}{l}\text { Myocardial } \\
\text { Infarction } \\
(\mathrm{N}=60)\end{array}$} & \multicolumn{2}{|c|}{$\begin{array}{c}\text { Heart } \\
\text { Disease } \\
(\mathrm{N}=805)\end{array}$} & \multicolumn{2}{|c|}{$\begin{array}{l}\text { Stroke } \\
(\mathrm{N}=69)\end{array}$} & \multicolumn{2}{|c|}{$\begin{array}{l}\text { Diabetes } \\
(\mathrm{N}=978)\end{array}$} & \multicolumn{2}{|c|}{$\begin{array}{c}\text { Oncological } \\
\text { Disorders } \\
(\mathrm{N}=228)\end{array}$} & \multicolumn{2}{|c|}{$\begin{array}{l}\text { Lung Disease } \\
\qquad(\mathrm{N}=761)\end{array}$} & \multicolumn{2}{|c|}{$\begin{array}{c}\text { Arthritis } \\
(\mathrm{N}=2,468)\end{array}$} & \multicolumn{2}{|c|}{$\begin{array}{l}\text { Osteoporosis } \\
(\mathrm{N}=1,139)\end{array}$} & \multicolumn{2}{|c|}{$\begin{array}{c}\text { Depressive } \\
\text { symptoms } \\
(\mathrm{N}=312)\end{array}$} & \multicolumn{2}{|c|}{$\begin{array}{c}\text { Anxiety } \\
\text { Symptoms } \\
(\mathrm{N}=248)\end{array}$} \\
\hline & & & & & & & & & & & & & & & & & & & & & & \\
\hline Medical information online & 633 & (25) & 8 & (13) & 209 & (26) & 18 & (26) & 205 & (21) & 86 & (38) & 202 & (27) & 643 & (26) & 296 & (26) & 44 & (14) & 43 & (17) \\
\hline Contact medical provider online & 558 & (22) & 4 & (7) & 186 & (23) & 11 & (16) & 194 & (20) & 67 & (29) & 163 & (21) & 557 & (23) & 231 & (20) & 31 & (10) & 32 & (13) \\
\hline Medical insurance online & 304 & (12) & 2 & (3) & 115 & (14) & 4 & (6) & 110 & (11) & 42 & (18) & 96 & (13) & 299 & (12) & 121 & (11) & 15 & (5) & 17 & (7) \\
\hline \multicolumn{23}{|l|}{ Physical unreadiness } \\
\hline Difficulty Speaking or making self-understood & 148 & (6) & 8 & (13) & 57 & (7) & 11 & (16) & 73 & (7) & 17 & (7) & 62 & (8) & 158 & (6) & 78 & (7) & 34 & (11) & 32 & (13) \\
\hline Difficulty reading newspaper even with glasses & 108 & (4) & 8 & (13) & 58 & (7) & 5 & (7) & 53 & (5) & 5 & (2) & 46 & (6) & 109 & (4) & 61 & (5) & 24 & (8) & 19 & (8) \\
\hline Unable to watch TV across room with glasses & 30 & (1) & 2 & (3) & 17 & (2) & 0 & (0) & 18 & (2) & 3 & (1) & 15 & (2) & 26 & (1) & 18 & (2) & 8 & (3) & 6 & (2) \\
\hline Difficulty hearing phone & 47 & (2) & 1 & (2) & 18 & (2) & 2 & (3) & 19 & (2) & 4 & (2) & 16 & (2) & 45 & (2) & 24 & (2) & 10 & (3) & 4 & (2) \\
\hline \multicolumn{23}{|l|}{ Technical unreadiness } \\
\hline No recent internet use in the last month & 990 & $(40)$ & 31 & (52) & 328 & $(41)$ & 28 & (41) & 459 & (47) & 77 & (34) & 305 & $(40)$ & 972 & (39) & 450 & $(40)$ & 171 & $(55)$ & 111 & (45) \\
\hline No recent email or texting use in the last month & 873 & (35) & 26 & (43) & 295 & (37) & 30 & (43) & 408 & $(42)$ & 69 & (30) & 281 & (37) & 846 & (34) & 377 & (33) & 164 & (53) & 108 & (44) \\
\hline Does not have a working computer & 785 & (31) & 28 & (47) & 234 & (29) & 23 & (33) & 347 & (35) & 44 & (19) & 228 & (30) & 763 & (31) & 342 & (30) & 153 & (49) & 114 & (46) \\
\hline Does not have a working cellphone & 262 & (10) & 10 & (17) & 89 & (11) & 9 & (13) & 99 & (10) & 13 & (6) & 86 & (11) & 260 & (11) & 111 & (10) & 61 & (20) & 47 & (19) \\
\hline Has a computer, doesn't know how to use it & 68 & (3) & 2 & (3) & 24 & (3) & 3 & (4) & 24 & (2) & 3 & (1) & 22 & (3) & 57 & (2) & 30 & (3) & 15 & (5) & & (3) \\
\hline
\end{tabular}

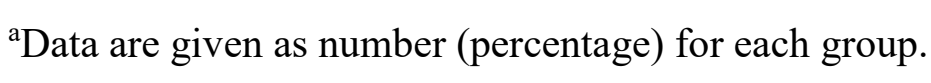


Table 3. Adjusted odds ratios for telemedicine readiness and unreadiness across medical conditions

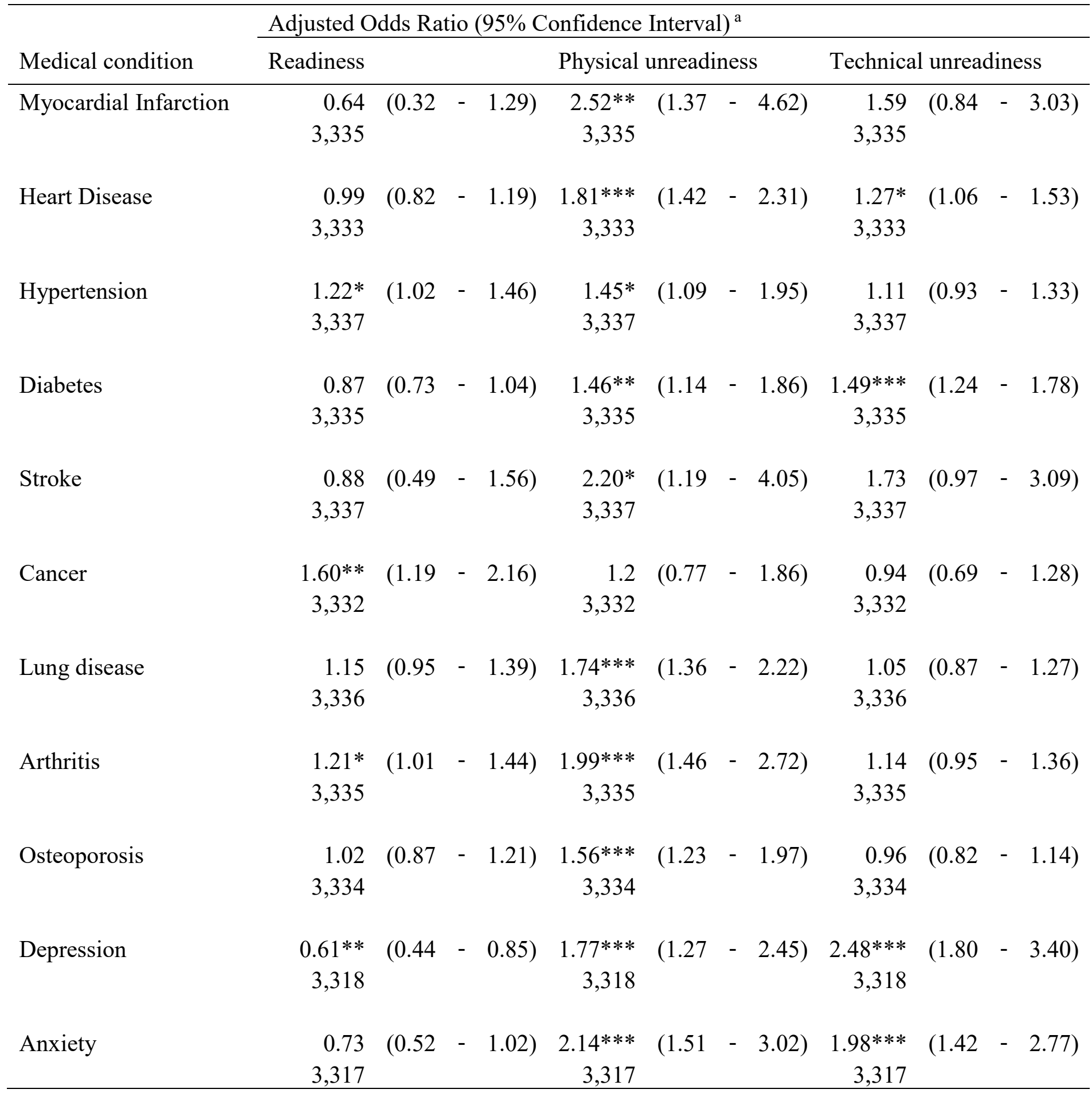

${ }^{\text {a }}$ Odds Ratios were estimated adjusting for age, gender, race/ethnicity, marital status and educational level.

$* P<.05$

** $P<.01$

*** $P<.001$ 